УДК 316

$10.17213 / 2075-2067-2021-4-53-56$

\title{
ФОРМАЛЬНЫЕ И НЕФОРМАЛЬНЫЕ ЗДОРОВЬЕСБЕРЕГАЮЩИЕ ПРАКТИКИ В СОВРЕМЕННЫХ УСЛОВИЯХ ${ }^{1}$
}

\section{(C) 2021 г. В. З. Зарбалиев}

\section{Южный федеральный университет, г. Ростов-на-Дону, Россия}

Целью исследования является изучение действий индивида по отношению к своему здоровью с точки зрения формальных и неформальных правил.

Методологическую базу исследования составляет теория институциональных изменений Д. Норта, где выделяются формальные и неформальные правила и механизмь принуждения.

Результаты исследования. Bыделение формальных и неформальных здоровьесберегающих практик позволило выявить эффективность их воспроизводства в конкретных жизненных ситуациях. Делается вывод, что в отдельных случаях высокая степень предрасположенности к неформальным здоровьесберегающим практикам базируется на стремлении индивида играть более самостоятельную роль по отношению к своему здоровью.

Ключевые слова: формальные практики; неформальные практики; здоровьесбережение; институцииональный подход.

\section{FORMAL AND INFORMAL HEALTH-SAVING PRACTICES IN THE MODERN CONDITIONS}

\section{(C) $2021 \quad$ V. Z. Zarbaliev}

\section{Southern Federal University, Rostov-on-Don, Russia}

The purpose of the study is to study the actions of an individual in relation to his health from the point of view of formal and informal rules.

The methodological basis of the research is the theory of institutional changes by D. North, where formal and informal rules and mechanisms of coercion are distinguished.

The results of the study. The identification of formal and informal health-saving practices made it possible to identify the effectiveness of their reproduction in specific life situations. It is concluded that a high degree of predisposition to informal health-saving practices is based on the individual's desire to play a more independent role in relation to his health.

Key words: formal practices; informal practices; health care; institutional approach.

1 Исследование выполнено при финансовой поддержке РФФИ в рамках научного проекта №20-311-90089 «Социальные практики здоровьесбережения молодежи в условиях трансформации российского общества». 
Введение. Существует значительное число практик поддержания здоровья, которые можно классифицировать по различным критериям. В данной работе предлагается рассмотреть действия человека по отношению к своему здоровью на основе их разграничения на формальные и неформальные практики. Имеющийся у индивида капитал оказывает существенное влияние на степень его приверженности к тем или иным практикам поддержания здоровья. Заботясь о своем здоровье, люди в определенных ситуациях могут отдавать предпочтение неформальным здоровьесберегающим практикам, такое поведение также может наблюдаться при наличии болезней. Соответствующее воспроизводство здоровьесберегающих практик способствует полноценной реализации потенциала индивида.

Основная часть. В научной литературе имеются дифференциальные представления о здоровьесбережении, которые определены парадигмами, в пределах которых авторы осуществляют исследование. В данной работе под здоровьесберегающими практиками понимается совокупность устойчивых и воспроизводимых действий индивидов, которые направлены на укрепление здоровья.

Различные аспекты здоровьесберегающих практик уже рассматривались в научной литературе. Однако рассмотрение вопросов, связанных с действиями по отношению к здоровью, с точки зрения формальных и неформальных правил еще не стали предметом основательного изучения ученых.

С. С. Шматова, выделяя типы здоровьесберегающих практик, отмечает, что «существуют как традиционные институционализированные практики сохранения здоровья (например, формы медицинского врачевания, которые могут быть обозначены как паттерналистские), так и практики, имеющие неформальный характер. Здесь следует выделить традиционные и альтернативные здоровьесберегающие практики, предлагающие собственные подходы к самосохранительному поведению» [1, с. 59].

В рамках теории институциональных изменений Д. Норт утверждает, что «институты - это принципы игры в обществе, и они возникают как ограничения, разработанные людьми для формирования политических, экономических и социальных взаимодействий. Они включают как неформальные ограничения, а именно санкции, табу, обычаи, традиции или принципы поведения, так и формальные принципы, такие как конституции, законы, права собственности» [2, с. 17]. Формальные и неформальные институты могут дополнять друг друга, то есть при неполноценном функционировании одного учреждения происходит компенсация со стороны другого.

Осуществляя анализ различий между формальными и неформальными правилами, В.В. Радаев замечает, что центральным моментом в этом плане является способ утверждения. Формальные правила закреплены в законах, и для них свойственна открытость и всеобщность. Помимо этого, формальные практики осуществляют несколько существенных функций применительно к неформальным правилам. Прежде всего, они в определенной степени играют роль ограничителя неформальных практик. Следующая функция связана с применением их в качестве инструмента по активизации принципиально новых неформальных практик [3]. Формальные правила при необходимости можно изменить за короткий промежуток времени, в то время как неформальные ограничения, выраженные в традициях, не поддаются за короткий промежуток времени трансформации.

У индивида есть выбор в плане воспроизводства формальных и неформальных практик. Формальные практики закреплены в законах, письменных предписаниях и могут носить характер обязательного выполнения. Примерами формальных здоровьесберегающих практик служат посещение врачей, прием лекарственных средств, диспансеризация, вакцинация и так далее.

В рамках социологического исследования ВЦИОМ, ориентированного на выявление способов сохранения здоровья, которым придерживаются россияне, было выявлено, что $35 \%$ россиян оценивают свое здоровье как хорошее, а 52\% - удовлетворительное [3].

Анализ собранных данных свидетельствует о том, что $37 \%$ россиян реализуют формальные здоровьесберегающие практики, такие как прохождение медицинского осмотра, диспансеризация, нахождение под наблю- 
дением врача, сдача анализов. В результате анализа результатов данного исследования выяснилось, что $44 \%$ респондентов осведомлены о возможности прохождения в России раз в год бесплатной диспансеризации или медицинского осмотра в государственном медицинском учреждении [3].

Опрос показал, что позиции о положительном эффекте диспансеризации расходятся приблизительно поровну: 44 \% приходится на респондентов, которые предполагают, что диспансеризация носит формальный характер и не способствует своевременному обнаружению ряда заболеваний; в то же время $40 \%$ опрошенных относятся к диспансеризации как к серьезной практике, которая позволяет вовремя выявить проблемы со здоровьем [3].

При возникновении проблем со здоровьем в некоторых ситуациях люди отдают предпочтение неформальным практикам, таким как самолечение, поскольку этот процесс сокращает финансовые расходы и экономит время. Самолечение незначительных травм способствует снижению общей нагрузки на систему здравоохранения [4].

Несмотря на то, что самолечение представляется формой самопомощи, которая в большинстве случаев реализуется для лечения симптомов незначительных заболеваний, такая практика при наличии серьезных заболеваний связана с некоторыми рисками: ошибочной самодиагностикой, заметным ухудшением состояния здоровья, при котором индивид производит попытки самостоятельного лечения, неблагоприятными лекарственными взаимодействиями.

Помимо имеющейся вероятности возникновения неблагоприятных последствий можно говорить о положительных сторонах самолечения на индивидуальном и общественном уровнях в определенных ситуациях. На индивидуальном уровне в качестве преимуществ самолечения выступают увеличение собственной роли в заботе о здоровье, сокращение финансовых расходов и экономия времени.

На общественном уровне среди преимуществ самолечения стоит отметить уменьшение случаев отсутствия на работе вследствие появления незначительных симптомов, увеличение объема помощи людям с серьез- ными заболеваниями и снижение нагрузки на оказание медицинских услуг.

Подавляющее большинство людей не владеют информацией о правилах приема лекарственных препаратов. Такое положение встречается в регионах, где у населения низкий уровень экономического, культурного и социального капиталов.

Заключение. В рамках статьи выявлены некоторые причины выбора индивидами формальных и неформальных здоровьесберегающих практик. Анализ этих факторов иллюстрирует, что в настоящее время принципиальное значение имеет работа над формированием и улучшением здоровьесберегающей компетентности, которая связана не только с выработкой определенных знаний, но и с повышением индивидуальной ценности здоровья. Институциональные соглашения оказывают воздействие на поведение индивидов, в то же время индивиды своими действиями создают институциональную среду.

\section{Литература}

1. Шматова С.С. Опыт социологической интерпретации практик здоровьесберегающего поведения // Известия Саратовского университета. Новая серия. Серия: Социология. Политология. - 2015. - Т. 15. - №2. C. 58-60.

2. Норт Д. Институты, институциональные изменения и функционирование экономики / Пер. с англ. А.Н. Нестеренко. М.: Фонд экономической книги «Начала», 1997. - $180 \mathrm{c}$.

3. Радаев B.B. Деформализация правил в российской хозяйственной деятельности // В книге: Кто и куда стремится вести Россию? Акторы макро-, мезо- и микроуровней современного трансформационного процесса. M., 2001. - C. 253-261.

4. Bennadi D. Self-medication: A current challenge // Journal of Basic and Clinical Pharmacy. - 2014. - №5 (1). - Pp. 19-23.

5. Диспансеризация как сохранить здоровье? Аналитический обзор [Электронный pecypc]. - Режим доступа: https://wciom. ru/analytical-reviews/analiticheskii-obzor/ dispanserizacija-kak-sokhranit-zdorove. 


\section{References}

1. Shmatova S.S. Opyt sociologicheskoj interpretacii praktik zdorov'esberegajushhego povedenija [Experience of sociological interpretation of health-saving behavior practices] // Izvestija Saratovskogo universiteta. Novaja serija. Serija: Sociologija. Politologija [News of the Saratov University. A new series. Series: Sociology. Political science]. — 2015. — Vol. 15. №2. - - Pp. 58-60.

2. Nort D. Instituty, institucional'nye izmenenija i funkcionirovanie jekonomiki [Institutes, institutional changes and the functioning of the economy] / Per. s angl. A. N. Nesterenko [Translated from English by A.N. Nesterenko]. - Moscow: Fond jekonomicheskoj knigi «Nachala», 1997. — 180 p.
3. Radaev V.V. Deformalizacija pravil v rossijskoj hozjajstvennoj dejatel'nosti [Deformalization of rules in Russian economic activity] // V knige: Kto i kuda stremitsja vesti Rossiju? Aktory makro-, mezo- i mikrourovnej sovremennogo transformacionnogo processa [In the book: Who is trying to lead Russia and where? Actors of macro -, mesoand micro-levels of the modern transformation process]. - Moscow, 2001. - Pp. 253-261.

4. Bennadi D. Self-medication: A current challenge // Journal of Basic and Clinical Pharmacy. - 2014. — №5 (1). — Pp. 19-23.

5. Dispanserizacija kak sohranit' zdorov'e? Analiticheskij obzor [Medical examination how to preserve health? Analytical review] [Jelektronnyj resurs]. — URL: https://wciom.ru/ analytical-reviews/analiticheskii-obzor/dispanserizacija-kak-sokhranit-zdorove.

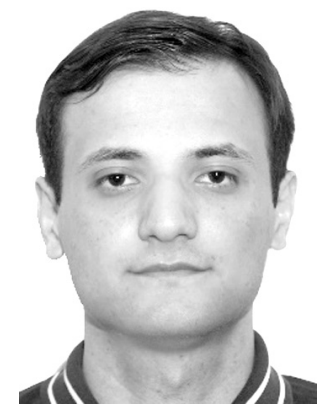

Зарбалиев Вадим Загиддинович - аспирант, стажёр-исследователь Института социологии и регионоведения Южного федерального университета. Сфера научных интересов - социология медицины и регионоведение.

Zarbaliev Vadim Zagiddinovich - Postgraduate Student, Research Assistant, Institute of Sociology and Regional Studies, Southern Federal University. Research interests - sociology of medicine and regional studies.

344006, г. Ростов-на-Дону, ул. Пушкинская, 160 160 Pushkinskaya st., 344006, Rostov-on-Don, Russia E-mail: zarbalievv@mail.ru 